\title{
The legal self: Executive processes and legal theory ${ }^{\text {th }}$
}

\author{
William Hirstein*, Katrina Sifferd \\ Department of Philosophy, Cognitive Science Lab, Elmhurst College, 190 Prospect Ave, Box 113, Elmhurst, IL 60126, United States
}

\section{A R T I C L E I N F O}

\section{Article history:}

Available online $\mathrm{xxxx}$

\section{Keywords:}

Executive processes

Legal agency

Criminal responsibility

Psychopathy

Intention

Planning

Hypnosis

\begin{abstract}
A B S T R A C T
When laws or legal principles mention mental states such as intentions to form a contract, knowledge of risk, or purposely causing a death, what parts of the brain are they speaking about? We argue here that these principles are tacitly directed at our prefrontal executive processes. Our current best theories of consciousness portray it as a workspace in which executive processes operate, but what is important to the law is what is done with the workspace content rather than the content itself. This makes executive processes more important to the law than consciousness, since they are responsible for channelling conscious decision-making into intentions and actions, or inhibiting action. We provide a summary of the current state of our knowledge about executive processes, which consists primarily of information about which portions of the prefrontal lobes perform which executive processes. Then we describe several examples in which legal principles can be understood as tacitly singling out executive processes, including principles regarding defendants' intentions or plans to commit crimes and their awareness that certain facts are the case (for instance, that a gun is loaded), as well as excusatory principles which result in lesser responsibility for those who are juveniles, mentally ill, sleepwalking, hypnotized, or who suffer from psychopathy.
\end{abstract}

(c) 2010 Elsevier Inc. All rights reserved.

\section{Legal agency and the brain}

There is currently a huge gap between the understanding our legal system has of the human self as rational, responsible decision-maker and the understanding of the human brain offered by neuroscience. The civil and criminal legal systems refer to the mind and mental processes when they speak of peoples' intentions, plans, motives, and beliefs. Not all mental states or processes are equally important to the law, however. Our contention in this article is that a close reading of legal principles shows that when they direct attention to the mind, they focus primarily on the brain's prefrontal executive processes. Executive processes are the seat of a person's decision-making, intention-forming, planning, and behavior-inhibiting processes, all of which are absolutely crucial to his legal and ethical being. Hence we call the set of executive processes "the legal self."

We will argue that neuroscience is an important tool for understanding the connection between mental processes and legal, or illegal, actions. We will also begin to establish correspondences between knowledge of the brain and established legal principles. This project can ultimately result in more just and appropriate verdicts, by clarifying the nature of human intention, planning, and decision-making and their disorders, especially those that are beyond the normal person's ability to correct. The brain's executive processes have been repeatedly singled out, albeit tacitly or non-explicitly, as the grounds of agency and responsibility by legal theorists and the law itself. We will argue that when referring to mental states and processes associated with illegal actions, the law is referring to these executive processes in the same way that a person who

\footnotetext{
This article is part of a special issue of this journal on "Brain and Self: Bridging the Gap".

* Corresponding author. Address: Department of Philosophy, 190 Prospect Ave., Box 113, Elmhurst, IL 60126, USA. Fax: +1 6306174609.

E-mail address: williamh@elmhurst.edu (W. Hirstein).
} 
refers to water is also referring $\mathrm{H}_{2} \mathrm{O}$ molecules, whether she knows it or not. Legal agency, including the capacity to make contracts and commit crimes, requires one to be able to form certain mental states and to act upon them. Similarly, intentions are vital to the formation of a contract: contracts are the legal crystallization of mutual intentions. Legal questions about agency, intent, and responsibility involve our conceptions of ourselves and of how our minds and our actions relate. The legal self is important, both for individuals who possess them, as well as the societies in which they are embedded.

We will begin with an examination of the views of legal scholar Stephen Morse, according to whom the legal system focuses on consciousness and rationality. Our response to this is that the focus is more on our executive processes than on consciousness itself. Our current best theories of consciousness portray it as a workspace in which executive processes operate (Baars \& Steven, 2005), but what is important to the law is what is done with the workspace content rather than the content itself. This makes executive processes more important to the law than consciousness itself, since they are responsible for channelling conscious decision-making into intentions, plans, and actions, or inhibiting those actions. On the topic of rationality, our views are closer to Morse, but we will argue that both our everyday and legal concepts of rationality can be captured by the concept of proper functioning of our executive processes. Section three details the current state of our knowledge about executive processes, which consists primarily of information about which portions of the prefrontal lobes perform which executive processes. Then our final section, section four, contains several examples in which legal principles can be understood as singling out executive processes, including principles regarding defendants' intentions or plans to commit crimes and their awareness that certain facts are the case (for instance, that a gun is loaded), as well as principles about the competence and/culpability of persons who are juveniles, mentally ill, sleepwalking, hypnotized, or who suffer from psychopathy.

\section{The legal self as the rational self}

A survey of American jurisprudence over the last two centuries reveals a continuing articulation of legal agency in commonsense psychological terms (Blumenthal, 2007). Legal agency, including the capacity to make contracts, and the capacity to commit a crime, require that one be able to form certain mental states and act on them. For example, one must be capable of forming the intention to create a binding last testament or will, and then knowingly complete the legal procedures to formalize those intentions. Susan Blummenthal calls these minimal psychological requirements for legal agency the 'default legal person': "To be sure, the default legal person was a shifty character, fading into the background of many judicial opinions and appearing in different guises as he moved across doctrinal fields.... But all the while, and arguably to the present day, the default legal person has served the same basic function: establishing the relationship between mental capacity and legal responsibility in any given case" (Blumenthal, 2007)(1149). Blummenthal argues that the law tends to elucidate these psychological or mental capacities in terms of consciousness and reason. "Apparent rationality" is not sufficient for legal capacity; in addition, an action must have been the product of the actor's conscious choice (Blumenthal, 2007)(1175). "[T]he default legal person. . .was capable of understanding the nature and consequences of his actions, and freely determining how to proceed on the basis of this knowledge. An individual shown to be in possession of these basic mental attributes would be held accountable for his actions..." (Blumenthal, 2007)(1175).

Morse - whose work focuses on the intersection of law and psychology - articulates a modern legal self that agrees with Blummenthal's formulation. Morse argues that legal agency is primarily concerned with the ability to reason: that is, to be a legal agent one must be capable of recognizing and acting for good reasons (Morse, 2003, 2006a, 2006b). This capacity for reason is often visible, or apparent, to both the agent and the law via the agent's consciousness. Most obviously, an agent reveals his or her conscious beliefs and desires through speech - verbal or written - and this speech is introduced to the court through witness testimony or written documents. In other cases, a court may be asked to extrapolate from behavioral evidence to a person's conscious states; e.g., in cases where a jury is asked to attribute motive to a criminal defendant from evidence that he was observed purchasing the murder weapon.

According to Morse we evolved conscious rationality precisely because we are social creatures who use this ability in addition to a set of rules to live cooperatively (Morse, 2003)(60). Morse states that "If the criminal law operates by guiding the conscious actions of persons capable of understanding the rules and rationally applying them, it would be unfair and thus unjustified to punish and to inflict pain intentionally on those who did not act intentionally or who were incapable of the minimum degree of rationality required for normatively acceptable cooperative interaction. People who lack the capacity for rational guidance are not morally responsible and should not be held criminally culpable" (Morse, 2003)(61). According to Morse, consciousness itself can be "integrated" or diminished, and can thus indicate a defendant's psychological capacity or incapacity. "Law and morality agree that if an agent's capacity for consciousness is non-culpably diminished, responsibility is likewise diminished" (Morse, 2003). At times, Morse appears to privilege consciousness: he claims consciousness can be diminished either because action without consciousness is not deemed to be action, or because diminished consciousness reduces the capacity for rationality. ${ }^{1}$ It is clear, however, that the link between consciousness and responsibility depends upon rationality. Where consciousness is diminished, moral and legal rules fail to provide an agent with reasons for action in the normal way.

\footnotetext{
${ }^{1}$ Or, it might seem, the other way round: the capacity for rationality is reduced, and this is expressed via a diminished consciousness.
} 
Thus, Morse and other legal scholars conceive of excusing conditions for legal liability as cases where an agent is not fully conscious (in the normal way) or capable of rational thought. Legal insanity is an obvious case. The M'Naughten rule states that a person is legally insane if he or she is "laboring under such a defect of reason, from disease of the mind, as not to know the nature and quality of the act he was doing; or, if he did know it, that he did not know he was doing what was wrong" (Rex v. M'Naughten, 1843). If a defendant truly believes, for example, that her son is about to be abducted by the devil, and that throwing him out a 10th-story window was the only way to save him from eternal hellfire, then she is thought to lack a normal understanding of the act's circumstances and consequences. In this way, she is incapable of rationally guiding her behavior.

Morse acknowledges that the capacity for rationality is physically instantiated, most likely in the human brain. However, he is hesitant to use psychology or neuroscience as a means of evidence of this capacity (or its lack) in defendants. Although "there is accumulating evidence that various psychological processes have their biological substrates in localized regions in the brain," Morse believes that this evidence doesn't speak to the capacity for rationality or consciousness per se, because the way the brain enables the mind is still unknown (Morse, 2008)(28). Although Morse describes himself as "a thorough-going, matter-up materialist who believes that all mental and behavioral activity is the causal product of lawful physical events in the brain," (Morse, 2006b) he is a non-reductive physicalist who believes that the way in which the brain enables consciousness remains "fundamentally mysterious." ${ }^{2}$ He thus argues that neuroscience, at least in its current state, should not be used in criminal trials. Instead, the court should stick to direct behavioral evidence to determine if a defendant lacks of the minimal consciousness or rationality required for responsibility.

The writings of Morse tend to run both consciousness and rationality together: when he claims that a responsible agent has a "fully integrated consciousness;" what he means is that the person "is capable as acting for reasons" (Morse, 2007). He sometimes mentions rationality, and other times consciousness, as diminished or faulty in cases where an agent is not fully responsible. We agree that the formulation of the legal self as the rational self is in a sense correct, and we accept as evidence of this that the law has had much success in categorizing persons with regard to criminal responsibility or legal capacity. However, we disagree that consciousness and rationality are interchangeable, and that consciousness alone is as reliable an indicator of the legal self as rationality. In addition, by de-emphasizing the role of consciousness we can keep the vexing problems associated with it from preventing us from making progress toward a neuroscientific articulation of the substrates of the legal self. Our approach allows for a clear distinction between consciousness itself, and the executive processes that operate on its contents.

One may wonder why a neuroscientific understanding of the legal self is necessary, as we have already indicated that the law's use of a folk understanding of the self as a rational actor is at least adequate to describe what mental states and processes are relevant. As the recent increase in the use of scientific psychology in the law shows, the folk approach has its limitations that science can be used to correct. Commonsense psychology, the tool judges and juries use to attribute mental states (and thus rationality), operates via something close to cognitive heuristics whereby mental states are attributed based on theoretical assumptions regarding human behavior and outward behavioral cues. ${ }^{3}$ Thus, as trial attorneys know well, it can be manipulated. Criminal verdicts are subject to a variety of arguably unreliable influences and behavioral data that push and pull commonsense mental state attributions in different directions. For example, by not allowing juvenile offenders to shave, and by dressing them in clothes a size too small, criminal prosecutors may make their request to transfer the juvenile to adult court more convincing.

Courts are increasingly turning to expert witness testimony and scientific psychology to shore up their commonsense notions and better classify defendants, especially those with diminished legal capacity. For example, in the 2005 Supreme Court case Roper v. Simmons, the US Supreme Court barred capital punishment of juveniles who killed while they were under the age of eighteen (2005). In the US most states use age together with the severity of the offense, in conjunction with other factors, when determining whether a juvenile defendant should be transferred up to adult court (Butts \& Mitchell, 2000). Consideration of age appears to be a heuristic for mental capacity; but consideration of severity of offense is clearly not a good indicator of capacity, and appears to be used because states consider juveniles who commit particularly violent crimes more deserving of retribution, despite their mental capacity. Other factors used to transfer juveniles are also far-fromsatisfactory heuristic methods of determining mental capacity. For example, under California's Welfare and Institutions Code 707(a), the juvenile judge must evaluate the degree of 'criminal sophistication' exhibited by the child.

Amicus Curiae briefs filed prior to the Roper decision strongly encouraged the court to utilize evidence from neuroscience in their assessment of juvenile culpability. The American Medical Association, the American Bar Association, the American Psychiatric Association, and the American Psychological Association all filed or subscribed to amicus briefs urging abolition of the juvenile death penalty based in part on the neuroscientific findings (Morse, 2006). Morse, however, argued that the neuroscientific evidence offered by the amici in Roper added nothing to the behavioral evidence already available to the court, claiming that the scientific evidence just served to distract the court from the real problem of assessing juvenile capacity for rationality in commonsense terms (Morse, 2006). In the end, the Roper majority opinion cited much scientific psychology,

\footnotetext{
${ }^{2}$ Morse states that "Most fundamentally, action and consciousness are scientific and conceptual mysteries. We do not know how the brain enables the mind, and we do not know how action is possible." (2007, p. 2555).

3 See Sellars, W. (1956). Empiricism and the philosophy of mind. In H. Feigl \& M. Scriven (Eds.), The foundations of science and the concepts of psychoanalysis, Minnesota studies in the philosophy of science (Vol. 1, pp. 127-196). Minneapolis, MN: University of Minnesota Press. Fodor, J. (1987). Psychosemantics: The problem of meaning in the philosophy of mind. Cambridge, MA: MIT Press. Dennett, D. (1991). Real patterns. Journal of Philosophy LXXXVIII, $27-51$.
} 
some of it based on neuroscience. Noting that juveniles are more subject to peer pressure and that they have less control over their environments, Kennedy then cited an article by Steinberg and Scott which noted that brain development in regions implicated in judgment and decision-making continue to develop well into late adolescence (Steinburg \& Scott, 2003).

Other cases where scientific psychology has been used to inform designations of legal capacity in criminal defendants include cases of mental retardation (Atkins v. Virginia, 2002); legal insanity (Panetti v. Quarterman, 2007); sleepwalking (R v. Parks, 1992); and psychopathy (People v. Dugan, 1985). As Nicole Vincent argues, “...To be a responsible moral agent one must have the right mental capacities, but since mental capacities are implemented in brain mechanisms (in brain "hardware"), to be a responsible moral agent one must have the right brain mechanisms..." (Vincent, 2008). This trend in criminal law supports our project of describing the legal self in neuroscientific terms: while analysis of consciousness and rationality works well, in many cases it isn't the best tool in our modern toolbox for categorizing legal agents. Below, we ground the trend toward the legal system's use of scientific psychology by providing a theoretical framework for a neuroscientific description of the legal self.

\section{An alternative approach}

At the moment, the sciences of the mind and brain (these include neuroscience, psychology, linguistics, philosophy, and portions of computer science), can be divided into two competing paradigms: the classical approach, centered around artificial intelligence and the computer model of the mind; and a new competitor, the neuroscience-based approach that employs anatomical and physiological descriptions, linked to behavior via cognitive neuropsychology. Despite some major differences between the two paradigms, there is an emerging consensus on the idea that cognition can be thought of as involving two primary components: representations, and capacities for manipulating those representations. A distinction between representations and processes performing functions on them is congenial to cognitivist approaches in psychology and cognitive neuroscience. For instance, Sternberg says that, "underlying most cognitive approaches to intelligence is the assumption that intelligence comprises mental representations (such as propositions or images) of information and processes that can operate on such representations" (Sternberg, 2010). It is much less widely appreciated, however, that neuroscience has lately been coming around to a very similar view. Neuroscientists speak of executive processes as those brain processes that act on and manipulate representations contained in a conscious workspace. This suggests a simple and intuitive way to think of the relation between consciousness and rationality. We are conscious of representations, but to be rational is to use your representations in certain ways. This distinction is crucial for the legal realm in that we hold people responsible for what they do with their thoughts and representations, rather than for them alone.

\subsection{Consciousness and executive processes}

Baars has developed a cognitive theory of consciousness according to which "conscious experience in general can be viewed as information presented to prefrontal executive regions for interpretation, decision-making and voluntary control" (Baars, Ramsøy, \& Laureys, 2003)(673). Baars and his co-authors say that, "conscious experience emerges from a nervous system in which multiple input processors compete for access to a broadcasting capability; the winning processor can disseminate its information globally throughout the brain" (Baars, 1993)(282). Representations are held in consciousness so that they can be further processed by any of a number of executive processes. Recently, neuroscientists have suggested that something of the sort Baars posits could be accomplished by the working memory areas located in the dorsolateral prefrontal cortex coupled with multimodal sensory integration areas in the posterior of the cortex (Dehaene et al., 2001). The executive processes exist in the dorsolateral prefrontal cortex, while the representations they manipulate exist in posterior sensory areas.

If consciousness is a workspace where representations are held online and manipulated, what manipulates them? A great deal of what we normally call thinking, deciding, planning and remembering is accomplished primarily by the brain's executive processes. There is an ongoing debate about how exactly to parse the set of executive functions, but the following tend to appear in most lists: attention, remembering, decision-making, planning, intending, and inhibiting. Gilbert and Burgess (2008)(10) say that, "executive functions are the high-level cognitive processes that facilitate new ways of behaving, and optimise one's approach to unfamiliar circumstances." Executive processes play a part in all non-routine actions. When we attempt something new, executive processes are required; they are needed when there are no effective learned input-output links. As we get better at the new task, processing moves to other brain areas that specialize in efficiently performing routine actions without conscious interruption. Routine actions, some of which exist in the brain's procedural memory, do not require executive activity to operate. As Miller and Wallis pithily state it, "You do not need executive control to grab a beer, but you will need it to finish college" (Miller \& Wallis, 2009). According to Gilbert and Burgess, "we particularly engage such processes when, for instance, we make a plan for the future, or voluntarily switch from one activity to another, or resist temptation; in other words, whenever we do many of the things that allow us to lead independent, purposeful lives" (Gilbert \& Burgess, 2008).

Most executive processes reside in the prefrontal lobes, including the dorsolateral frontal lobes on the side of the brain, the ventrolateral frontal lobes below them, the medial prefrontal lobes, on the inner surfaces of the two hemispheres, and the orbitofrontal lobes located on the brain's undersurface just above the eye sockets (Moscovitch \& Winocur, 2002). Our 
information about executive processes comes from three separate data sources: First, the study of brain anatomy, especially its connectivity. Second, humans who have prefrontal lesions have been carefully studied to determine which mental functions have been compromised by the damage. Third, brain imaging. Subjects are given tasks requiring executive intervention, and their brains are imaged as they solve the tasks. One introspectively accessible measure of the amount of executive activity is our sense of mental effort. Increased mental effort correlates with increased usage of oxygen by executive areas, which is detectable by brain imaging.

\subsection{Executive functions}

Our understanding of the brain's cortex has progressed from back to front. The first areas we were able to clearly assign function to were the unimodal perceptual areas, whose responses could be mapped to the sense organs themselves. We have now reached the front of the brain, which contains its highest-level mental operations, achieved by executive processes. If we read the reports of brain anatomists and physiologists who investigate executive processes, we can begin to see the familiar mental functions we know both via our own minds and via commonsense psychology.

As we noted above, executive processes are required for non-routine cognition. A portion of the anterior cingulate cortex, in the medial prefrontal cortex located on the inner surface of the two hemispheres, is frequently found to be active during effortful processing. The anterior cingulate is thought to play a role in resolving conflicts between routine actions that are not relevant to the present task, and novel actions that are relevant. It is located just above the front of the corpus callosum, and connects to several parts of the prefrontal cortex in addition to the orbitofrontal cortex, including dorsolateral and medial areas. In their review of the anatomy and function of the anterior cingulate cortex, Devinsky et al. say that it "assesses the motivational content of internal and external stimuli and regulates context-dependent behaviors" (Devinsky, Morrell, \& Vogt, 1995)(279). They divide the anterior cingulate into an affect region, which assesses "motivational content," and a cognitive region, which goes into action during "cognitively demanding information processing," and which also has dense connections to motor areas. Areas 32 and 24 are also important for error detection (Carter, Braver, et al., 1998; Garavan, Ross, Murphy, Roche, \& Stein, 2002). They activate strongly when experimental subjects detect errors in their responses (Carter et al., 1998), and they then interact with behavioral inhibition areas in the dorsolateral prefrontal cortex (i.e., areas 44 and 9) to effect an inhibition of the erroneous response.

\subsubsection{Attention}

We perceive the world across a large bandwidth, but we need to focus on certain parts of the incoming flow in order to maximize the effectiveness of our behavior. There are at least two different attentional systems. The first is "rapid, saliencydriven and bottom-up" whereas the second is "slower, volitionally controlled and top-down. Each form of attention can also be more diffuse or more focused" (Crick \& Koch, 2003). Top-down attention is an executive process and has a focusperiphery structure that is most obvious in the visual modality, but is present in all of them. In contrast, bottom-up attention is more evenly distributed throughout the visual field, for instance in our ability to detect moving objects (Koch, 2004), although as noted above, even this form of attention can be focused. The executive portion of the anterior cingulate cortex fulfills two of the roles that an area embodying attention should perform. It receives input from both sensory and mnemonic systems and it also shows activity in brain imaging studies consistent with a role in attention. The posterior portions of the dorsolateral prefrontal cortex (i.e., areas 8 and rostral 6) also support top-down attentional executive processes. We direct attention not only to portions of the incoming perceptual flow, but also to our own memories. The brain apparently uses some of the same tricks to do both. Barbas, Ghashghaei, Rempel-Clower, \& Xiao, 2002 say that the role of the orbitofrontal cortex in selective attention to memories is "analogous to the functions of the frontal eye fields in directing [visual] attention and medial area 10 in directing auditory attention to currently relevant stimuli" (Barbas et al., 2002).

\subsubsection{Recognition}

It is important to note that the executive processes can participate in the act of recognition itself, and that they normally have the power to overrule our initial perceptual identifications. For example, when you seem to hear someone in your house at night, executive processes can take control and manage the gathering of additional information - for instance, by eliciting a memory that a tree branch hits a certain window when the wind blows - and use this memory to negate the thought of burglars. This requires holding the memory online and directing attention back and forth between it and attention to the sound outside. We might thus distinguish between initial identification and considered identification. We all experience strange perceptions at times, but we are able to correct them using executive processes. I believe I see my friend during a trip to Nepal, but then I realize how improbable that is-this friend never travels, has no interest in Nepal, etc.-so I do not allow myself to recognize that person as my friend.

\subsubsection{Memory}

When you remember, especially something from your personal past, you often provide a cue for your memory to work from. When you want to remember someone's name, for instance, you picture her face. When you are trying to recall a specific event, you will typically recall related events, in order to better reconstruct the event you are interested in. We can also check memories against other memories, of both the autobiographical and semantic variety. You believe you remember seeing Bill Clinton give a campaign speech in August of 1990, but then a check against your semantic memory conflicts with this, 
since the presidential campaign would not have commenced yet. It must have been August of 1991, you conclude. Executive processes used the existing memories to cue other memories, and managed the resolution of the inconsistency. Correctly reporting events from memory does not simply involve reading off what the memory record contains. It is a reconstructive process, involving interaction between executive processes and the memory store. Johnson and her colleagues distinguish between heuristic checking of candidate memories, which is usually operating when we are remembering, and systematic checking which is "engaged selectively and deliberately." Heuristic processing "uses readily available information (e.g., familiarity), including qualities (e.g., perceptual detail) and schemas (e.g., world knowledge, stereotypes) activated by a cue" (Johnson, Hayes, D’Esposito, \& Raye, 2000)(362). Systematic processing involves several different executive functions. It requires selective attention: the person must explicitly attend to the candidate memory.

\subsubsection{Decision making}

Studies support the idea that executive functions are essential to decision-making by showing that damage to certain executive systems can produce poor decision-making. For instance cognitive neuropsychologist Antonio Damasio's patient E.V.R., who had ventromedial frontal damage due to a brain tumor, failed to use past experience and knowledge of what was likely to happen in the future when he made decisions, with disastrous results including failed marriages and businesses (Damasio, 1995). In general, E. V. R. failed to inhibit unwise actions. Shimamura notes that thinking of the function of the prefrontal lobes as filtering, or inhibiting "may also be useful in explaining the kinds of social disinhibition observed in patients with orbital prefrontal lesions.... Such patients exhibit a failure to inhibit inappropriate social behaviors (e.g., telling crude jokes, emotional rages)" (811).

Duncan and Owen argue that mid-dorsolateral (the upper surface of the frontal lobes), mid-ventrolateral (the lower surface), and dorsal anterior cingulate cortex form a system that accomplishes several executive tasks, including resolving response conflicts, managing working memory, and responding to perceptual tasks (Duncan \& Owen, 2000). Areas 9 and 46 (jointly known as mid-dorsolateral prefrontal cortex) function to monitor and manipulate information held in working memory (Moscovitch \& Winocur, 2002). Lesions to this area in the brains of monkeys impairs their ability to track and keep in mind multiple stimuli (Petrides, 2005)(5649). Owen and his colleagues (Owen, Evans, \& Petrides, 1996) have theorized that the ventrolateral prefrontal cortex serves to activate and hold online information located in posterior cortices (D’Esposito, Postle, et al., 1999), while the dorsolateral prefrontal cortex monitors and manipulates this information. Area $47 / 12$ of the ventrolateral prefrontal cortex subserves the conscious, explicit encoding and retrieval of information into and from memory. This involves "processing initiated under conscious effort by the subject and guided by the subject's plans and intentions" according to Petrides (2005)(791).

\subsubsection{Action and its planning}

The executive system has several output systems that it uses to create effective actions. "All areas of the prefrontal cortex have access to specialized motor control systems" (Barbas et al., 2002). Action planning is an important part of decisionmaking. Planning involves devising effective sub goals, and recalling task-relevant information, all of which is managed by executive processes. Another important feature of planning is that the sequence of actions must be carefully worked out. Miller and Wallis (2009) provide the example of a patient with a frontal lobe tumor who first stirred her coffee, then added milk. Executive processes are required to disengage from one task, and engage in another. Task switching is currently one of the experimental paradigms of choice for scientists who study executive processes. The classic experimental test of this is called the Stroop test. The subject must say aloud which color ink each word in a list is printed in. The difficulty is that the words themselves are the names of colors, so that the word "blue," for instance, is printed in yellow ink. Executive processes are required in order to inhibit ourselves from simply reading the word, and answering "blue." This produces a slight, but measurable, delay in our responses, as well as a sense of increased mental effort (Miller \& Wallis, 2009).

The frontal pole is at the highest-level of processing and appears to play a role in keeping track of more complicated cognitive tasks, ensuring that the steps needed to accomplish them are executed in the right order. After reviewing several theories of the function of area 10, Ramnani and Owen (2004) conclude that what they all share is the idea that this area is responsible for coordinating information processing and transfer among different prefrontal areas (Ramnani \& Owen, 2004). More specifically, they argue that area 10 becomes involved when two or more separate cognitive operations must be performed to accomplish a task. Area 10 keeps track of these operations, for instance by ensuring that they are performed in the correct order. Barbas and Zikopoulos also offer an account consistent with this: "Area 10 has a key role in complex working memory tasks that require juggling of multiple tasks. ., such as interrupting reading a book to answer the telephone then remembering to resume reading at the place of departure" (Barbas \& Zikopoulos, 2007)(538). Petrides says that, given its anatomical constitution and connectivity, area 10 "is in an ideal position to monitor the monitoring process in the middorsolateral prefrontal cortex, namely to engage in what might be called 'hyper-monitoring'. This sort of hyper-monitoring would be "critical in multi-tasking and high-level planning" (Petrides, 2005)(790). Burgess suggests that area 10 working together with the right dorsolateral prefrontal cortex is involved in the "creation and maintenance of intentions" (Burgess, 2000)(470). When executive systems are damaged, actions seems to be generated bottom-up rather than top-down (Humphreys, Forde, \& Francis, 2000).

The orbitofrontal cortex is the highest-level area of the ventral cortical functional network, and one of the ultimate destinations for the ventral visual processing stream, the stream that functions primarily to allow us to detect, categorize, and associate reward values with objects, and people. Barbas and Zikopoulos describe area 13 as having "a role in evaluating the 
significance of stimuli" (Barbas \& Zikopoulos, 2007)(540). We also noted above that orbitofrontal cortex plays a role in inhibiting imprudent or socially inappropriate actions.

\section{Points of connection: Neuroscience and the law}

In this section we will describe several points at which legal principles are implicitly directed at the executive processing capacities of agents. These include the voluntary/involuntary distinction, the delineation of mental states required for criminal responsibility, the troublesome case of sleepwalking, and other possible justifications or excuses to criminal responsibility.

\subsection{The voluntary act and mental state requirements}

To be found guilty of a crime in the United States a defendant must be found to meet two criteria: he must have committed an act deemed criminal, and he must possess a certain mental state with regard to this act. The first of these criteria is called the actus reus (which literally means guilty act) requirement. The actus reus requirement is met only if a defendant is found to have committed a criminal act voluntarily. The second criterion is called the mens rea (which means guilty mind) requirement, which is met if the defendant has certain mental states with regard to the criminal act.

The criminal law requires an act or omission that comprises the physical elements of a crime as stipulated by statute, this is the actus reus requirement. But while this requirement is primarily concerned with a defendant's act, it also refers to the defendant's mental states: an act is voluntary only if it has some minimal connection to the defendant's goal states or desires. An example of an involuntary act is a case in which a person has an epileptic seizure while driving (with no history of such seizures, and thus no reason to suspect one would occur). If the seizure causes the driver to swerve off the road and kill a pedestrian he would not be guilty due to a failure to the meet the actus reus requirement. Similarly, if a malevolent person trips a jogger who then falls onto an elderly lady, causing her to break a hip, the jogger is not responsible due to the lack of a voluntary act. As prominent legal scholar HLA Hart has noted, an unconscious act or an act by reflex is not really a human action at all, and thus for an act to be culpable there must be a "minimum link between mind and body" (Hart, 1968).

Legislators and the courts have largely defined the voluntary act condition by exclusion. According to US Model Penal Code (MPC), a statutory text developed to assist state legislatures in updating and standardizing their criminal codes, the following cannot be considered voluntary acts: a reflex or convulsion, a bodily movement when unconscious or asleep, conduct during hypnosis, and movement not produced by effort of the actor (e.g., someone is forced to hold a gun and then her finger is pushed against the trigger by someone else's hand). ${ }^{4}$ Other possibilities, depending on jurisdiction, include movements while "brainwashed," during dissociation or automatism not during sleep (e.g. unconsciousness caused by severe bodily injury), and movements that are part of a habitual act. In cases of reflex, convulsion, or where the bodily movement is not produced by effort of the actor, there is no relationship between the bodily movement that caused harm and the actor's desires. In the case of hypnosis, one might argue that the bodily movement that causes harm is actually linked to the hypnotist's desire, not the actor's.

The second requirement for criminal culpability is the mental state, or mens rea, requirement. Even where it is determined that a criminal act has been committed voluntarily, in most cases (those not involving strict liability) there must be some specific relationship between a defendant's desires and the criminal harm caused. ${ }^{5}$ Imagine stumbling over a person passed out in the park at midnight. It might be the case that you desired to put your foot exactly there, in that place where the man was, and that as a result of this desire you injured him. However, even though what you did was voluntary, you are not guilty of battery because you didn't "intentionally apply unlawful force" - that is, you didn't desire to cause him harm, even though you desired to put your foot there. ${ }^{6}$ In the case of murder, a person might pull the trigger of a gun and thus take a human life - fulfilling the actus reus requirement for murder - but not intend or desire to take a human life. Instead he might have, under extreme conditions, reasonably believed he was shooting a bear. In both cases, the act requirement seems to be met for the particular crime, but the mental state requirement is not.

The mental state requirement also relates to a defendant's beliefs or informational states. For the requirement to be met, in many cases a defendant must: (1) possess specific desires to perform an act, (2) possess those desires within certain circumstances of which he is aware, and (3) know that the act, once performed, will have certain consequences. For the most severe crimes like first-degree homicide, there is often a further requirement that the defendant (4) desire that the postulated consequences will actually occur. For example, the act requirement for theft requires that the defendant take possession of property that does not belong to him. The mental state requirement for theft calls for two additional mental states: that the defendant know he is not entitled to the property, and that he have the desire to deprive the rightful owner of possession permanently.

\footnotetext{
${ }^{4}$ (1985). Model Penal Code and Commentaries (Official Draft and Revised Comments). §2.01. Hereafter MPC.

${ }^{5}$ Strict liability offenses are those where, for policy reasons, the standard for proving culpability has been lowered so a mental state element is not required. A common example is statutory rape: a person can be found guilty of statutory rape even if he didn't know the person he was having sex with was underage. As a matter of policy, the law asks persons to bear the burden of finding out the age of their partner before they have sex.

${ }^{6}$ See MPC $\$ 2.02$
} 
The two most important mental concepts that form a bridge from the legal concepts above to the language of neuroscience are intention and planning. As we will discuss below, the MPC standards requiring defendants to engage in acts purposefully and knowingly both involve having specific intentions to commit a particular act, and some planning to perform that act. Neuroscientists do not shy away from using either term, and their uses are largely consistent and coherent, in that they fit our ordinary uses of the terms. If Burgess is correct in stating that area 10 in the polar prefrontal cortex, as well as the right dorsolateral prefrontal cortex, are involved in the "creation and maintenance of intentions" (Burgess, 2000)(470), legal theorists should be interested in these two areas. Planning also involves recalling items from memory, verifying them, and merging them with other representations and plan segments already in consciousness. This would require activation of executive processes to verify the recalled memories. It would involve the ventrolateral cortex to hold relevant information, contained in the posterior cortices, online while the dorsolateral cortex, under the direction of the polar cortex, manipulated that information. While all this is happening, executive sectors of the anterior cingulate are monitoring the process for errors or inconsistencies, capable of producing a strong alerting signal via the autonomic system when one is found. Disorders of this planning and decision-making process are relevant to a defendant's guilt and degree of responsibility. Now the crucial questions are directed at the person's ability to notice and correct for any of these disorders.

\subsection{Purposely, knowingly, recklessly, negligently}

The Model Penal Code has classified the types of mental states required for criminal responsibility into four categories, which generally correspond to different levels of culpability. The categories refer specifically to the relationship between the defendant's desires or beliefs and the harm caused by a criminal act. An act can be done purposely, knowingly, recklessly, or negligently. ${ }^{7}$ According to the MPC, "purposely" means that the defendant consciously desired that his act have a particular result. "Knowingly" means that the defendant was aware that his act would (very likely) have a particular result, even if he didn't directly desire the outcome. ${ }^{9}$ This distinction may or may not be relevant with regard to a particular crime. For example, one might think that this distinction would matter for the purposes of determining level of culpability in a homicide, but it does not. A case where a defendant lit a house on fire with the intention of killing the person sleeping inside, and a case where the defendant lit the house of fire to scare the occupant (knowing there was a good chance he would not escape the fire) are both likely to constitute first-degree murder.

One example of a crime that requires the defendant act with purpose is theft, mentioned above, which requires that the criminal act be done with the purpose of permanently depriving another person of his or her rightful property. In some cases, however, full culpability for a crime only requires proof of the less strict mental state of knowing. For example, to be convicted of the federal crime of importing an illegal drug into the US, one need only know one is doing so. Similarly, to be convicted of selling illegal drug paraphernalia, one need only know the paraphernalia can be used to administer illegal drugs. One need not in addition be selling the items with that explicit purpose. A defendant is deemed reckless when he is aware of a risk that his act may have a particular result, yet performs it anyway. A homicide committed recklessly is treated differently from one committed purposely or knowingly. For example, in many states unintentionally killing another person while recklessly engaged in an action that is likely to cause death or great bodily harm constitutes involuntary manslaughter, an offense that carries significantly lesser penalties than first-degree murder. ${ }^{10}$ An example might be offering drunk teens bungee cord jumps off a high bridge when the cord has been improperly tied or is worn.

A negligent state of mind means that the defendant should have been aware of a risk that his act might cause a particular harmful result, even though he was not aware. With regard to recklessness and negligence, it is usually also required that the risk of harm be substantial and unjustifiable. ${ }^{11}$ The distinction between recklessness and negligence is a difference between what the defendant knows regarding possible consequences of his action (in other words, his level of foresight). In this case the bungee cord jump operator may have consistently failed to inspect his equipment, but not actually known the cord was very likely to break. A reckless defendant knew there was a chance of substantial harm; a negligent defendant did not know but should have. In some cases this failure to foresee harmful consequences can rise to the level of "willful blindness" and a "wanton disregard for human life" as is required for corporate manslaughter. What a person should have known is determined by the rational person standard: that is, would an ordinary person of normal cognitive faculties have known there was a risk of

\footnotetext{
7 See generally, MPC §2.02, and MPC §2.06-2.08.

8 MPC $\S 2.02(2)(a)$ Purposely. A person acts purposely with respect to a material element of an offense when: (i) if the element involves the nature of his conduct or a result thereof, it is his conscious object to engage in conduct of that nature or to cause such a result and (ii) if the element involves the attendant circumstances, he is aware of the existence of such circumstances or he believes or hopes that they exist.

${ }^{9}$ MPC $\$ 2.02(2)(b)$ Knowingly. A person acts knowingly with respect to a material element of an offense when: (i) if the element involves the nature of his conduct or the attendant circumstances, he is aware that his conduct is of that nature or that such circumstances exist and (ii) if the element involves a result of his conduct, he is aware that it is practically certain that his conduct will cause such a result.

10 For example, see Illinois statute 720 ILCS 5/9-3(a), which states that "A person who unintentionally kills an individual without lawful justification commits involuntary manslaughter if his acts whether lawful or unlawful which cause the death are such as are likely to cause death or great bodily harm to some individual, and he performs them recklessly, except in cases in which the cause of the death consists of the driving of a motor vehicle or operating a snowmobile, all-terrain vehicle, or watercraft, in which case the person commits reckless homicide."

11 The MPC recognizes one further state of mind, 'willful blindness', where a defendant is aware that there is a high probability that he is committing a crime, but intentionally avoids ascertaining the facts.
} 
harm? This standard usually stipulates average capacity, but it may be stricter in certain cases. For example, to prove medical malpractice, a physician must fail to exhibit the standard of care accepted for a person of his profession and expertise.

With regard to the difference between a reckless and negligent state of mind, awareness will function as a crucial bridge concept between neuroscience and the law, but the concept of attention is also relevant. These two concepts can function together to capture the legal notion of an agent who should have been aware of something. We are only fully aware of things, people and events after we have directed our attention toward them. Numerous experiments in psychology and cognitive neuroscience attest to this (Mack \& Rock, 1998; Rensink, O'Regan, et al., 2003). A typical experiment of this sort allows the subject to examine a photo of scene for several seconds. Then the subject is shown the same photo with something in it altered. No matter how obvious the alteration is, if the subject did not explicitly attend to that detail and consciously register it, a large percentage of them do not notice the change (Rensink, O'Regan, et al., 2003). If we accept this, one way to analyze what it means to say that someone should have been aware of something means that the person's attention should have been directed toward it. This means that the law is saying that an executive process, attention, should operate in certain ways in certain situations.

A possible objection here is that the relevant brain process is consciousness rather than executive processing, contrary to what we suggested above. Indeed, the awareness being spoken about is conscious awareness and "attention" of course refers to conscious attention. However, "attention" means more than just that an item is at the "center' of consciousness. It is possible to stare directly at something while not being aware of it. A more specific and accurate concept of awareness is that one is aware of an item if it has been brought into contact with the brain's executive centers, and which may now perform manipulations on it. Similarly, the definition in the Model Penal Code of a purposeful action entails that the agent consciously desires a certain outcome. The importance of consciousness in this definition is not, we suggest, due to the importance of consciousness itself, but rather because those representations brought into consciousness are those representations exposed to the agent's executive processes. It is not the consciousness that is doing the crucial mental work, it is the executive processes. A desire that has been brought into consciousness has been exposed to the sort of action inhibiting processes based in ventromedial prefrontal cortex. Desires that are exposed to executive processes and not eliminated or prevented from causing behavior will then become that agent's considered desires. The agent has had the opportunity to eliminate or check them, but has failed to do so. If she then commits a criminal act, information regarding these considered desires is relevant to her guilt.

Note what is gained by focusing on the executive processes instead of consciousness: in a particular subject we can perform a detailed analysis of where the process of consideration or decision-making might have broken down, and whether this breakdown was due to the subject's limited capacity, or due to the failure to apply his fully functioning capacities. In the former case, lesser responsibility might be appropriate due to an excuse (see below); in the latter, responsibility and punishment might be fully warranted, although it could hinge on the law's desire to encourage people to use these capacities. In sum, it seems that where the law demands one commit an act purposely, knowingly, or recklessly, an offender must have engaged his executive functions with regard to that act, although he would have paid lesser attention to the consequences of the act in the case of an act committed recklessly. However, in the case of negligence, it seems executive functions are not engaged with regard to the criminal act - but in the eyes of the law, they should have been.

\subsection{Excuses and justifications}

If the prosecution fails to convince a judge or jury that the defendant either meets the voluntary act or the mental state requirement the defendant cannot be found guilty of a crime. ${ }^{12}$ However, even if both elements of the crime have been proven, the defendant can still attempt to make a plausible argument as to why he shouldn't suffer punishment. A defendant can attempt to justify his act by claiming that it advanced some social interest, or prevented a greater wrong. Or, he can attempt to excuse his act by arguing that he merits exculpation and should not be held blameworthy. Typically, justification defenses include 'choice of evils' or duress arguments. The insanity defense and a defense of intoxication are typically considered defenses of excuse. ${ }^{13}$ If we are right that the legal self consists the agent's set of executive processes, then we should be able to explain many excuses and justifications in terms of abnormality or malfunction in executive processing. While we cannot address every legal excuse and justification here, we will discuss two excuses that have traditionally resulted in lesser culpability: the insanity defense and juvenile status. We will also discuss sleepwalking cases and the case of psychopaths, who some have argued should have lesser culpability.

\subsection{Sleepwalking}

Although, as indicated above, acts performed while asleep are not considered voluntary by the Model Penal Code, sleepwalking has proven to be a particularly difficult case for the courts. Movements produced while sleepwalking may be related

\footnotetext{
12 Failure of proof defenses include things such as the defense of mistake or accident, discussed above. A mistake defense is merely a way of explaining why the prosecution has failed to prove the mental intent requirement.

13 Legal doctrine can be somewhat confusing on this point, however, because many of the defenses discussed below, including insanity and intoxication, can also be considered to show the defendant lacked the requisite mental state, which would mean the defendant would not need to present a defense (as the prosecution failed to make a case against him).
} 
to some desire or other of the person, even though those acts are not produced in the normal way. For this reason some courts have characterized cases where a defendant appears to be credibly sleepwalking as cases where the sleepwalker's act is voluntary, but where the requisite mens rea is lacking, and others have categorized sleepwalking offenders as legally insane. Consider the well-known Parks case (R v. Parks, 1992). Parks was a 23-year-old Toronto man with a wife and infant daughter. He was suffering from severe insomnia caused by joblessness and gambling debts. Early one morning in 1987 he got out of bed, got into his car and drove $23 \mathrm{~km}$ to his in-laws' home, where he stabbed his mother-in-law to death and assaulted his father-in-law, who survived. He then drove to a police station and said, "I think I have killed some people. . .my hands," seeming to only realize at that moment that he had severely cut his own hands. ${ }^{14}$ There was evidence that Parks had a good relationship with his in-laws and he had no apparent motive for the crime. He also had a history of sleepwalking. His team of defense experts concluded that he was in a state of automatism at the time the crime was committed, and thus had not committed a voluntary act. Dr. R. Billings, a psychiatrist from the University of Toronto, testified as follows ${ }^{15}$ :

"Probably the most striking feature of what we know of what goes on in the mind during sleep is that it is very independent of waking mentation in terms of its objectives and so forth. There is a lack of control of directing our minds in sleep compared to wakefulness. In the waking state, of course, we often voluntarily plan things, what we call volition - that is, we decide to do this as opposed to that - and there is no evidence that this occurs during the sleepwalking episode."

In response to the question of whether the defendant, if he was sleepwalking at the time of the crime, would have had the capacity to intend, Dr. Billings answered 'No'. Parks was acquitted of all charges.

In a 1988 case of sleepwalking in the UK, however, the court took a different view of the excuse of sleepwalking. In this case the defendant attacked a friend who was sleeping on his couch, striking her with a bottle and attempting to strangle her before he awoke and called an ambulance. The court determined the defendant, Burgess, was suffering from a sleep disorder based on testimony that sleepwalking is ". . . an abnormality of brain function, so it would be regarded as a pathological condition (R v. Burgess, 1991)."16 This expert also opined that persons suffering from the disorder should be detained in a hospital "...because it is a treatable condition." In the end, the court held that Burgess was not guilty by reason of insanity.

In normal human beings there is a mechanism functioning to keep the brain activity that occurs in deep sleep from initiating action. In REM Behavior Disorder, however, a lesion in the brain stem causes the loss of muscle atonia usually present during REM, and one may act out the dreams one is having in REM sleep. Patients with this disorder complain of vivid, repetitive, and sometimes violent dreams. While still asleep these people often yell, punch, and kick, sometimes causing injury. While most agree that RBD is a clear disorder of the bypass of the motor system that usually occurs during REM sleep, some argue because the violent nature of the dream-enacting behavior RBD is also a psychological disorder. Sleepwalking, however, also occurs during stage 2 or non-REM sleep (Guilleminault, 1995). The sleeper suddenly starts to perform motor and/or verbal activity but remains asleep, as demonstrated by EEG. The individual is not aware of the activity, and unless awakened fully by others during the episode, will have total amnesia of the event (Sharp \& D’Cruz, 2002).

REM sleep is marked by a pronounced absence of executive activity. Imaging studies show that while the brain's emotional centers are active, including orbitfrontal and orbitomedial cortices, the executive centers housed primarily in the dorsolateral cortex are inactive (Maquet, 2000) in both REM and non-REM sleep. We can verify this via introspection simply by recalling how uncritical we are in dreams. We are especially uncritical of our "perceptions": in dreams, people turn into other people right before us and we happily accept that and dream on. Normally such strange perceptions would arouse executive activity as the agent struggles to interpret them. In the Parks case, when the testifying psychiatrist spoke of the lack of volition during sleepwalking, and the lack of ability to "voluntarily plan things" in the sleepwalking state, he was speaking about executive processes, we would submit. Associating a person's legal agency with proper executive function would thus work in this sort of case to limit the sleepwalker's culpability. He was in a state in which executive activity would not be expected to happen. We cannot say, "He should have realized what he was about to...," etc., because sleeping people can't do this. Thus it makes sense to excuse sleepwalkers from their crimes, because the mental state requirement could not be fulfilled: the sleepwalker cannot be "purposeful", "knowing" or "reckless", all of which require some executive activity, and he can't be accused of negligence because he couldn't have been expected to engage in executive activity.

Our analysis reinforces the law's general assumption that a person who commits an act while sleepwalking should not be held responsible for her acts. However, there is some question whether the MPC is correct to classify such acts as "involuntary." These acts seem intentional in a way that acts committed during an epileptic seizure or acts "not caused by volition of the actor" are not: there is, using Hart's definition, a "minimal connection between mind and body." Sleepwalking cases also seem substantively different from cases of legal insanity. As we will discuss below, in many cases a person suffering from mental illness has executive processes that are engaged, but significantly deficient in their operations. It thus seems that sleepwalking should be considered a failure of proof case, where a defendant is deemed not guilty due to lack of the requisite mens rea. ${ }^{17}$

\footnotetext{
14 A summary of facts in this case can be found in Lawrence, Martin 'Can Sleepwalking be a Murder Defense', at www.mtsinai.org/pulmonary/sleep/sleepmurder.htm.

15 Testimony quoted from E Law - Murdoch University Electronic Journal of Law, Vol. 3, No. 1 (May 1996).

${ }^{16}$ A summary of facts in this case can be found in Lawrence, Martin 'Can Sleepwalking be a Murder Defense', at www.mtsinai.org/pulmonary/sleep/sleepmurder.htm.

17 See Morse 1984 for an argument that cases of diminished mental capacity should be considered failure of proof cases.
} 
There is an interesting similarity between cases of sleepwalking and hypnosis, another state in which acts produced are considered involuntary by the MPC. Subjects who are hypnotized seem to retain some connection between desires or goal states represented within the actor's cognitive system and acts performed, and thus such acts seem voluntary. However, some have argued that in cases of hypnosis a person's executive functions appear to be disengaged (Farvolden \& Woody, 2004; Woody \& Bowers, 1994). It has also been suggested that some persons who are highly suggestible in hypnosis can be characterized by deficits in executive functioning (Terhune, Cardea, et al., 2010). A study by Gruzelier and Warren (1993) found decreased executive functioning during hypnosis consistent with what has been termed the dissociatedcontrol model, which argues that executive processes are disengaged in hypnosis, allowing the hypnotist to originate some degree of motor and information-processing activity in the person hypnotized. Other studies have emphasized the similarities between cases of hypnosis and some cases of frontal lobe damage, where patients also suffer from disengagement of the executive system (Aikens \& Ray, 2001). One way to interpret these findings is that the hypnotist is acting as a stand-in for the disengaged executive functions of the hypnotized actor. If this is true, in the case of legitimate hypnosis, as in sleepwalking, it would seem that the person who commits the act lacks the requisite mens rea to be held responsible because his or her executive functions are suppressed or disengaged.

\subsection{Insanity}

In some jurisdictions, if a defendant was insane at the time the crime was committed a determination of legal insanity may wholly exculpate him due to lack of the requisite mens rea. One example is a burglary case where the defendant was under the delusion that he owned the apartment and its contents (See People v. Wetmore 22 Cal.3d 318 (1978)). In the majority of jurisdictions, however, a not guilty by reason of insanity (NGRI) plea is not considered a failure to prove mens rea but instead a defense - an excuse for the act - which qualifies the defendant for special status. According to this view defendants with a mental illness are not considered as morally responsible as other defendants, and thus they are generally sentenced to a hospital or a prison for the criminally insane instead of prison, where they are generally held until considered 'cured' of their illness.

Courts have been largely unsuccessful in determining legal insanity using medical terminology. For example, an attempt by courts to use the Durham test, a test meant to focus on the medical evidence of mental disorder, failed. The test required that the criminal act be the "product of a mental disease or defect" (Durham v. United States, 1954). Most jurisdictions in the US use one of two standards to determine whether a defendant is insane: either the 1843 M'Naghten test, or the test promulgated in the MPC. The M'Naghten test focuses on the requirement that a defendant possess a "defect of reason" resulting in an inability to discern right from wrong, requiring that "at the time of the committing of the act, the party accused was laboring under such a defect of reason, from disease of the mind, as not to know the nature and quality of the act he was doing, or if he did know it that he did not know what he was doing was wrong" (Rex v. M'Naughten, 1843). Thus this test for insanity focuses upon cognitive impairment.

Compared to the M'Naughten test, the MPC lowers the insanity standard from an absolute knowledge of right from wrong to a substantial incapacity to appreciate the difference between right and wrong. The MPC also broadens the insanity test to include a volitional or "irresistible impulse" component: to be determined insane a defendant must either be unable to appreciate the difference between right and wrong or must be unable to conform his conduct to the requirements of the law. Sixteen states currently have an insanity statute that allows a defendant to qualify based upon volitional defect alone, without requiring any cognitive impairment (Donohue, Arya, et al., 2008). The American Psychiatric Association has argued that volitional tests may be unnecessary because defendants with significant volitional impairment usually suffer from significant cognitive impairment as well (Donohue et al., 2008). However, those in favor of preserving a volitional test claim that debilitating but treatable psychiatric disorders, such as bipolar disorder, result in loss of volitional control, while cognitive knowledge and appreciation of wrongfulness/criminality remain intact (Donohue et al., 2008).

The use of the insanity defense is rare. On average the insanity defense is raised in less than $1 \%$ of all felony cases, and is only successful in about $15-25 \%$ of the cases in which it is raised (Borum \& Solomon, 1999). Those acquitted tend to be charged with more serious offenses, older, more physically attractive, more educated and have a less extensive criminal history (Rice and Harris, 1990). Between $60 \%$ and $77 \%$ of those deemed legally insane are diagnosed with a psychosis (Gurley \& Marcus, 2008). As we will discuss below, evidence of psychopathy is much less likely to result in an acquittal (Gurley \& Marcus, 2008).

A person who is experiencing hallucinations is only mentally incompetent if she believes her hallucinations. As we noted above, the brain's executive processes have the power to reject perceptions and memories as false. Executive processes, when functioning normally, seem able to correct for just about any defect in perception. We all experience strange thoughts on occasion, the feeling that someone is watching us; the odd notion that we had a causal influence on something where no reasonable physical explanation is available (e.g., I flip a light switch and a car horn honks outside); the idea that others can read our thoughts. But we are able to reject these thoughts and not let them establish themselves as beliefs because we have the cognitive processes required to assess their plausibility. A person with delusions, however, is not mentally competent because she believes her delusions. This indicates an executive problem; in order for strange and/or implausible thoughts to become beliefs, there needs to be a second problem at the cognitive level (in addition to the first factor, responsible for generating the delusional belief to begin with). A two-factor hypothesis of delusions finds its first full explicit form in 2000 (Langdon \& Coltheart, 2000), followed a year later by a more general version of the hypothesis (Davies, Coltheart, et al., 2001). More recently, the nature of the executive problems leading to the failure to reject anomalous beliefs has been 
described in greater detail (McKay, Langdon et al., 2007). When the writers of the M'Naghton standard spoke of a "defect of reason" they were singling out executive processes, we suggest, specifically a failure to respond in a rational way to what is contained in one's consciousness.

Because of this, we feel that cases where a criminal defendant suffers from a hallucination or delusion, where the hallucination or delusion is directly related to the crime committed, are cases where the defendant should be legally excused from his act. Similarly, where a defendant, due to a serious mental illness, suffers from severe dysfunction in executive processes, or a lack of executive processing, the legal self is properly considered "insane" and thus excused from culpability. Persons with progressive schizophrenia, for example, often exhibit severe deficits in tasks testing attentional set shifting, online use of working memory, and planning and strategy capacity (Hutton, Puri, et al., 1998). In such cases it seems clear that a lack of executive function due to mental illness ought to excuse a defendant due to cognitive impairment - and that evidence of volitional capacity is unnecessary.

In keeping with the views of the American Bar and American Psychiatric Associations, our analysis also leads us to disagree with current shift allowing "guilty but mentally ill" (GBMI) verdicts. In 2000, at least 20 states had instituted GBMI provisions. GBMI statutes include a finding that the defendant was mentally ill at the time the crime was committed, but that he or she fails to meet the requirements for legal insanity. Such a category seems unnecessary. Either the defendant's executive processes were severely compromised at the time the crime was committed, or they were not. If they were, the person lacks mental capacity and thus is not culpable. We might agree with the GBMI verdict if it offered lesser culpability for mentally ill defendants who suffered from substantial, but not severe, problems with executive functioning. But first, using executive function as the gauge for legal insanity is something we are now suggesting; it is not a currently a common tactic for offering or assessing evidence of mental capacity. Second, the verdict is not used to apply lesser culpability to those with lesser levels of mental illness. A defendant who receives a GBMI verdict is still considered legally guilty of the crime in question, but since he is mentally ill, he is entitled to receive mental health treatment while in prison. If the defendant's symptoms remit while in prison he is required to serve out the remainder of his sentence. (A defendant who was acquitted by reason of insanity, on the other hand, must be released from his treatment facility if it is determined he is no longer dangerous to himself or others.) Third and finally, many studies have determined that the inclusion of a GBMI provision has significant impact on juror verdicts in that jurors are less likely to hold a defendant not guilty by reason of insanity if they have a GBMI option (Callahan, McGreevy, et al., 1992; Caton, Golding, et al., 1987). This means that the GBMI verdict may be allowing jurors to ignore the moral or legal consequences of relevant evidence of mental illness.

Our contention is that in the future, evidence of mental illness will become more standardized, and easier to understand, if presented in terms of executive function.

\subsection{Juvenile status}

Juveniles have traditionally been thought to have lesser criminal responsibility because they lack mental capacities important to decision-making and thus are more impulsive and easily manipulated (e.g., via peer pressure). Offenders below a certain age - traditionally in common law the age of 7 - were thought to be incapable of forming the mental intent required for any crime. In addition, the separate juvenile system of justice in the US, which applies less severe penalties than the adult system, can be seen as an outgrowth of the doctrine of diminished mental capacity. As mentioned above, most US states use some combination of age of offender and severity of offense, and possibly some other factors, to determine whether a young defendant should be transferred up to adult court, or should remain in the juvenile system (Butts \& Mitchell, 2000). Age is often thought to be a proxy for level of mental capacity. Severity of offense, on the other hand, seems to identify defendants most deserving of retribution. Some legislatures require any juvenile, regardless of age, to be transferred to adult court for certain offenses. For example, in West Virginia, any child who commits a violent criminal act must be transferred. In addition, several states provide judicial discretion to send any juvenile regardless of age to criminal court based on the specific offense. ${ }^{18}$

As stated earlier, in the 2005 case of Roper $v$. Simmons the Supreme Court categorically excluded offenders under eighteen from the death penalty in part due to diminished capacity. In his majority opinion Justice Kennedy cited much scientific psychology from amici briefs filed in the case. For example, noting that juveniles are more subject to peer pressure and that they have less control over their environments, Kennedy then cited an article by Steinburg and Scott (2003). Here is a section of the article Kennedy cited:

What is most interesting is that studies of brain development during adolescence, and of differences in patterns of brain activation between adolescents and adults, indicate that the most important developments during adolescence occur in regions that are implicated in processes of long-term planning (Spear, 2000)....[P]atterns of development in the prefrontal cortex, which is active during the performance of complicated tasks involving long-term planning and judgment and decision-making, suggest that these higher order cognitive capacities may be immature well into late adolescence (Giedd, 1999).

(Steinburg \& Scott, 2003)

\footnotetext{
${ }^{18}$ For a complete review of juvenile transfer provisions in the US, see the governmental website for the US Department of Justice's Office of Juvenile Delinquency and Prevention, located at http://www.ojjdp.ncjrs.gov/pubs/reform/contents.html.
} 
In this quotation Steinberg and Scott are referring to the slow development of gray matter in the prefrontal cortex. A large part of the development of the frontal lobes occurs between ages 5 and 10 (Case, 1992), and they do not fully mature until the teenage years (Smith, Kates, \& Vreizen, 1992). There are maturational improvements in frontal connectivity, both within the frontal cortex and with more distal regions (specifically the parietal cortex and basal ganglia, respectively) occurring into early adulthood (Baird \& Fugelsang, 2004). This maturation closely coincides with age-related behavioral improvements in working memory, as well as action planning and inhibition. The improved fronto-parietal connectivity that comes with age has also been found to be highly correlated with improvements in working memory (Olesen, Westerberg, \& Klingberg, 2004). Abigail Baird, whose research focuses upon juvenile decision-making, argues that because of these deficits, "it may be physically impossible for adolescents to engage in counterfactual reasoning, and as a result of this are often unable to effectively foresee the possible consequences of their actions" (Baird \& Fugelsang, 2004).

Interestingly, before the cortical areas that embody executive processes tasked with managing and verifying memories have matured, children make unreliable witnesses. Johnson and her colleagues note that children exhibit some of the same patterns of memory problems that frontal patients show (Lindsay, Johnson, \& Kwon, 1991). There are now several experiments showing that false memories can be induced in children by asking them leading questions (Ackil \& Zaragoza, 1998). Ceci et al. were able to produce false memories in preschool children. Children were presented with a deck of cards, each of which described an event (Ceci, Huffman, \& Smith, 1994). Some of the events had actually happened to the children, while others had not. When they were repeatedly asked whether the false events had happened to them, $58 \%$ of the children eventually agreed that they had, and many of them embellished the event with confabulated details.

As all children below a certain age appear to suffer from global deficits in executive function, we support a separate juvenile court system handling all criminal defendants below a certain age, regardless of the level of crime committed. This age should be determined by further research into the severity of deficit in executive function during different points of cognitive development. A more exact alternative would be to undertake a case-by-case analysis of the cognitive maturity (in terms of executive function) of juvenile defendants. However, we understand this approach would be costly and thus is unlikely to be adopted. We also understand that retributive sentiment may support sending juveniles who commit very serious crime to adult prisons. However, the principle of retribution goes hand in hand with the principle of proportionality; and punishment ought to be proportional to the type of offender, not just to the level of crime committed.

\subsection{Psychopaths}

As stated above, juveniles are both eligible to be excused from culpability or to have lesser culpability in accordance with the diminished mental capacity doctrine. In addition, there is conceptual overlap between the doctrines of legal insanity and diminished capacity because both can be used to indicate that a defendant was incapable of forming the requisite mental states for criminal guilt. The diminished capacity doctrine thus allows a criminal defendant to either negate a mental element of the crime charged, thereby exonerating the defendant of that charge, or to reduce the degree of the crime for which the defendant may be convicted, even if the defendant's conduct satisfies all the elements of a higher offense (Morse, 1984).

A fairly new and more controversial use of the diminished capacity doctrine is to claim that it qualifies psychopaths for lesser culpability. Recently defense attorneys have introduced fMRI and PET scan evidence of psychopathy along with other evidence of abnormal decision-making and behavior, in an attempt to argue that psychopaths suffer similar cognitive deficiencies to defendants who are more commonly considered to have diminished capacity, such as juveniles and the mentally retarded. ${ }^{19}$ Similarly, philosophers have argued that, due to a lack of certain mental capacities, it may be inappropriate to hold psychopaths fully responsible for their criminal acts (Fine \& Kennett, 2004).

For example, at the sentencing phase of Brian Dugan's capital trial for the 1983 kidnapping, rape and murder of a 10-yearold girl, neuroscientist Kent Kiehl, working for the defense, introduced fMRI evidence that Dugan had serious brain abnormalities similar to those who suffered from psychopathy. Dugan scored 37 out of a possible 40 on the Hare Psychopathy checklist, which placed him in the 99.5th percentile. The defense argued that Dugan had abnormal brain functioning typified by antisocial behavior, impulsivity, and an inability to feel sympathy or remorse. The defense used this evidence to make a general argument that Dugan was a psychopath, and that psychopaths suffer from diminished mental capacity, a mitigating circumstance in Illinois' capital sentencing statute. However, the jury eventually returned a verdict of the death penalty, despite Kiehl's testimony. ${ }^{20}$

Neuroscientist R. J. R Blair, among others, has argued that the functional contributions of the amygdala and ventromedial prefrontal cortex (vmPFC) are compromised in subjects with psychopathy (Blair, 2008a, 2008b). It appears that the amygdala may process emotional information, including information about the emotional states of those around us, sending this and other information to the vmPFC as information relevant to decision-making and action palnning. In an fMRI study of fearful expression processing, Marsh et al. (2008) reported reduced functional connectivity between the amygdala and the vmPFC in children with psychopathic tendencies relative to the comparison children. Moreover, Birbaumer, Veit, et al. (2005) reported reduced vmPFC activity as well as reduced amygdala activity in individuals with psychopathy during aversive conditioning (Birbaumer et al., 2005). Finally, psychopathic individuals show hippocampal and anterior cingulate impairment.

\footnotetext{
19 http://www.nytimes.com/2007/03/11/magazine/11Neurolaw.t.html.

${ }^{20}$ http://www.nature.com/news/2010/100317/full/464340a.html.
} 
Both Adina Roskies and Adrian Raine and colleagues have argued that psychopaths appear to show normal moral reasoning ability, but appear to fail to apply the outcome of such reasoning processes due the lack of emotional input described above (Raine \& Yang, 2006; Roskies, 2006). Roskies specifically argues that psychopaths have moral beliefs, but not the motivation to act upon them (Roskies, 2006). When asked to provide an answer to the famous "trolley" thought experiment where subjects are asked to decide whether to intentionally kill one person to save five - patients with ventromedial damage are more likely to judge that intentionally killing the one man (by pushing him onto trolley tracks) is the right thing to do. Thus, it is thought that persons with ventromedial damage may be more likely to engage in antisocial or immoral behavior, precisely because they do not feel badly about such action.

Given the basic separation between our representations and our executive processes, we have argued that the latter play a special role in legal agency and the legal self, while the former are much less important. Executive processes can correct for a wide variety of flaws in our set of representations. For instance, if you have a bad memory, you can correct for this by taking great care in making any claims based on your memory. And, as discussed above, even if you are hallucinating, if you know this you can correct for it by ignoring implausible visual input. This ability to correct for flawed perceptions or memories positions the set of executive processes as the final line of defense to prevent flawed representations from causing flawed, i.e., illegal behavior. Psychopaths have flawed perceptions in that they do not perceive other people as intrinsically valuable, at least in part because they fail to have the proper emotional input that would allow them to do so (Herpertz \& Sass, 2000). They have had abundant time and feedback to correct these perceptions, yet they do not do so.

Up to this point we have avoided answering the question of exactly what sort of executive damage, and what level of damage, is exculpatory. It seems inadvisable to make the weakness or total absence of a single executive process exculpatory, because many of the other executive processes are still capable of correcting for this weakness. Another reason for this is that we will all have stronger and weaker executive abilities, but we do not regard the presence of these weaknesses as exculpatory. If it is true, then, that psychopaths lack only a single executive process, this would not seem to be enough to relieve them of responsibility for their actions.

\section{Conclusion}

One way to see that these executive processes constitute a sort of self is to observe that we use that special word "I" in describing them. We say "I decided to do it," "I planned the event," "I realized it that it was not a bear," and even "I stopped myself from doing it." We take ownership of these processes, and we take responsibility for what is accomplished with them. They are the natural locus of our sense of responsibility and guilt. Understanding exactly how the brain plans actions and forms intentions can help us begin to discern whether certain types of injury to the areas that accomplish these might be exculpatory. But there are some obvious limits here. All rational persons are, perhaps by definition, capable of acting intentionally, so we do not foresee a point where neuroscience could establish that a defendant was incapable of forming any intentions whatsoever. There are nevertheless particular conditions in which neuroscience might provide evidence for or against the presence of the relevant intentions. Examples might include actions while under hypnosis or during a seizure. Neuroscience might also be able to show that a defendant was incapable of constructing a complicated plan, by showing that he had damage to polar prefrontal cortex, for example.

Despite the glacial pace at which change comes to the legal system, progress in the brain sciences is cause for optimism. A recent study found that its participants who acted as jurors were more likely to find a defendant not guilty by reason of insanity if they heard testimony about brain injury or saw images of brain damage (Gurley \& Marcus, 2008). The neuroimages used included MRI scans obtained from Anderson, Damasio, Tranel, and Damasio (2000) that showed extensive damage to the prefrontal cortex. The participants saw these scans and read testimony indicating that the prefrontal cortex "has been associated with impulse control and it is likely that because of the reduced volume in this area the defendant would have difficulty controlling his actions." The study's authors speculate that the reason for this is that

neuroimages and brain injury testimony provide more tangible evidence than is typically presented in psychological or psychiatric testimony. Unlike medical disorders, psychiatric disorders cannot usually be seen through blood test results or $\mathrm{X}$-rays; jurors have to rely on experts to make the diagnosis. The neuroimages of readily apparent brain damage give the jurors tangible proof of the disorder. The brain injury testimony may work in a different way: it provides the jurors with a clear cause and an effect. The defendant was normal prior to the brain injury and did not begin showing symptoms of a psychiatric disorder until after the brain injury, thus the brain injury must have caused the psychiatric disorder. (Gurley \& Marcus, 2008)(94)

Our set of executive processes is the most important, and final way that we have for making sure our actions are not criminal. As Gurley and Marcus note, "Combined, the brain injury testimony may have led jurors to believe that the defendant was unable to control his actions, due to no fault of his own, and the neuroimages provided conclusive proof that the defendant had suffered brain damage."(Gurley \& Marcus, 2008)(94)

Explicitly (as opposed to implicitly) focusing on the brain's executive processes can help open up the human planning and decision-making process to the view of the legal system. Understanding decisions and action in folk psychological terms i.e., using terms such as "intention," "knowledge," and "purpose" - is certainly helpful, but these terms can also invite error by making us think we understand more about the psychology of defendants than we do. Connecting these principles to solid neuroscience may be able to correct for any biases or hasty generalizations used in the law. 
Issues surrounding the notion of self are more commonly thought to involve questions about our identities, whereas the legal self primarily involves our responsibility for our actions. We have, however, exactly as much identity as we are able to claim responsibility for. Identity is not purely a social notion: there are personal consequences to identity choices as well. We have, to a carefully deliberated extent, the right to be who we are. But with identity comes responsibility. The legal self is that set of properties that simultaneously create this identity and this responsibility. It is that part of our psychology that is imperative for identity, and that the law attends to. It is vital to close the gap between our legal conceptions of self and the brain, so that our legal system can begin making finer-grained distinctions in its judgments of guilt, and of competency.

\section{Acknowledgment}

We gratefully acknowledge the research assistance of Krista Wiley.

\section{References}

Ackil, J. K., \& Zaragoza, M. S. (1998). Memorial consequences of forced confabulation: Age differences in susceptibility to false memories. Developmental Psychology, 34, 1358-1372.

Anderson, S. W., Damasio, H., Tranel, D., \& Damasio, A. R. (2000). Long-term sequelae of prefrontal cortex damage acquired in early childhood. Developmental Neuropsychology, 3(18), 281-296.

Aikens, D., \& Ray, W. J. (2001). Frontal lobe contributions to hypnotic susceptibility: A neuropsychological screening of executive functioning. The International Journal of Clinical and Experimental Hypnosis, 49(4).

Atkins v. Virginia, 536 US 304 (2002).

Baars, B. J. (Ed.). (1993). How does a stream of consciousness that is relatively simple, serial, and limited in capacity emerge from a brain that is largely unconscious, complex, and massively parallel? Ciba symposium on experimental and theoretical foundations of consciousness. London, UK: Wiley Interscience.

Baars, B. J., Ramsøy, Thomas Z., \& Laureys, Steven (2003). Brain, conscious experience and the observing self. Trends in Neurosciences, 26(12), 671-675.

Baars, B. J., \& Steven, L. (2005). Global workspace theory of consciousness: Toward a cognitive neuroscience of human experience. Progress in Brain Research, Elsevier, 150, 45-53.

Baird, A. A., \& Fugelsang, J. A. (2004). The emergence of consequential thought: Evidence from neuroscience. Philosophical Transactions of the Royal Society, 359(1451), 1797-1804.

Barbas, H., Ghashghaei, H. T., Rempel-Clower, N. L., \& Xiao, D. (2002). Anatomic basis of functional specialization in prefrontal cortices in primates. New York: Elsevier.

Barbas, H., \& Zikopoulos, B. (2007). The prefrontal cortex and flexible behavior. The Neuroscientist, 13(5), 532-544.

Birbaumer, N., Veit, R., et al (2005). Deficient fear conditioning in psychopathy: A functional magnetic resonance imaging study. Archives of General Psychiatry, 62(7), 799-805.

Blair, R. (2008a). The cognitive neuroscience of psychopathy and implications for judgments of responsibility. Neuroethics, 1(3), 149-157.

Blair, R. J. R. (2008b). The amygdala and ventromedial prefrontal cortex: Functional contributions and dysfunction in psychopathy. Philosophical Transactions of the Royal Society B: Biological Sciences, 363(1503), 2557-2565.

Blumenthal, S. L. (2007). The default legal person. UCLA Law Review, 54(5).

Borum, R., \& Solomon, M. F. (1999). Empirical research on the insanity defense and attempted reforms: Evidence toward informed policy. Law and Human Behavior, 23(1), 117-135.

Burgess, P. W. (2000). Real-world multitasking from a cognitive neuroscience perspective. Cambridge, MA: MIT Press.

Butts, J. A., \& Mitchell, O. (2000). Brick by brick: Dismantling the border between juvenile and adult justice. Boundary changes in criminal justice organizations. NIJ, US Department of Justice, Office of Justice Programs, 2, 167-213.

Callahan, L. A., McGreevy, M. A., et al (1992). Measuring the effects of the guilty but mentally ill (GBMI) verdict: Georgia's 1982 GBMI reform. Law and Human Behavior, 16(4), 447-462.

Carter, C. S., Braver, T. S., et al (1998). Anterior cingulate cortex, error detection, and the online monitoring of performance. Science, 280(5364), 747-749.

Case, R. (1992). The role of the frontal lobes in the regulation of cognitive development. Brain and Cognition, 20, 51-73.

Caton, F. R., Golding, S. L., et al (1987). Implicit theories of criminal responsibility: Decision making and the insanity defense. Law and Human Behavior, 11(3), 207-232.

Ceci, S. J., Huffman, M. L., \& Smith, E. (1994). Repeatedly thinking about a non-event: Source misattributions among preschoolers. Consciousness and Cognition, 3, 388-407.

Crick, F., \& Koch, C. (2003). A framework for consciousness. Nature Neuroscience, 6(2), 119-126.

Damasio, A. (1995). Descartes' error: Emotion, reason, and the human brain. Harper Perennial.

Davies, M., Coltheart, M., et al (2001). Monothematic delusions: Towards a two-factor account. Philosophy, Psychiatry, and Psychology, 8(2/3), 133-158.

Dehaene, S., Naccache, L., Cohen, L., Bihan, D. L., Mangin, J. F., Poline, J. B., et al (2001). Cerebral mechanisms of word-masking and unconscious repetition priming. Nature Neuroscience, 4, 752-758.

Dennett, D. (1991). Real patterns. Journal of Philosophy, LXXXVIII, 27-51.

D'Esposito, M., Postle, B. R., et al (1999). Maintenance versus manipulation of information held in working memory: An event-related fMRI study. Brain and Cognition, 41(1), 66-86.

Devinsky, O., Morrell, Martha. J., \& Vogt, Brent. A. (1995). Contributions of anterior cingulate cortex to behaviour. Brain: A Journal of Neurology, 118(1), 279-306.

Donohue, A., Arya, V., et al (2008). Legal insanity: An assessment of the inability to refrain. Psychiatry MMC March.

Duncan, J., \& Owen, A. (2000). Common regions of the human frontal lobe recruited by diverse cognitive demands. Trends in Neurosciences, 23(10), 475-483.

Durham v. United States, 214 F 2d 862 (1954).

Farvolden, P., \& Woody, E. Z. (2004). Hypnosis, memory, and frontal executive functioning. International Journal of Clinical and Experimental Hypnosis, 52(1), $3-26$.

Fine, C., \& Kennett, J. (2004). Mental impairment, moral understanding and criminal responsibility: Psychopathy and the purposes of punishment. International Journal of Law and Psychiatry, 27(5), 425-443.

Fodor, J. (1987). Psychosemantics: The problem of meaning in the philosophy of mind. Cambridge, MA: MIT Press.

Garavan, H., Ross, T. J., Murphy, K., Roche, R. A. P., \& Stein, E. A. (2002). Dissociable executive functions in the dynamic control of behavior. Neuroimage, 17, $1820-1829$.

Gilbert, S. J., \& Burgess, P. W. (2008). Executive function. Current Biology, 18(3), 110-114.

Gruzelier, J., \& Warren, K. (1993). Neuropsychological evidence of reductions on left frontal tests with hypnosis. Psychological Medicine, 23(1), 93-101.

Guilleminault, C. e. a. (1995). Forensic sleep medicine: Nocturnal wandering and violence. Sleep, 18, 740-748.

Gurley, J. R., \& Marcus, D. K. (2008). The effects of neuroimaging and brain injury on insanity defenses. Behavioral Sciences and the Law, 26(1), 85-97. 
Hart, H. L. A. (1968). Punishment and responsibility: Essays in the philosophy of law. Oxford: Clarendon Pres.

Herpertz, S. C., \& Sass, H. (2000). Emotional deficiency and psychopathy. Behavioral Sciences and the Law, 18(5), 567-580.

Humphreys, G., Forde, E. M. E., \& Francis, Dawn. (Eds.). (2000). The organization of sequential actions. Control of cognitive processes. Cambridge, MA: MIT Press. Hutton, S. B., Puri, B. K., et al (1998). Executive function in first-episode schizophrenia. Psychological Medicine, $28(02), 463-473$.

Johnson, M. K., Hayes, S. M., D’Esposito, M. D., \& Raye, C. L. (Eds.). (2000). Confabulation. Handbook of neuropsychology. New York: Elsevier.

Koch, C. (2004). The quest for consciousness: A neurobiological approach. Englewood, Colorado: Roberts and Company Publishers.

Langdon, R., \& Coltheart, M. (2000). The cognitive neuropsychology of delusions. Mind and Language, 15, 184-218.

Lindsay, D. S., Johnson, M. K., \& Kwon, P. (1991). Developmental changes in memory source monitoring. Journal of Experimental Child Psychology, 52, 297-318.

Mack, A., \& Rock, I. (1998). Inattentional blindness. Cambridge, MA: MIT Press.

Maquet (2000). Functional neuroimaging of normal human sleep by positron emission tomography. Journal of Sleep Research, 9(3), 207-231.

Marsh, A. A., Finger, E. C., Mitchell, D. G. V., Reid, M. E., Sims, C., Kosson, D. S., et al. (2008). Reduced amygdala response to fearful expressions in children and adolescents with callous-unemotional traits and disruptive behavior disorders. American Journal of Psychiatry, 165, 712-720.

McKay, R., Langdon, R., et al (2007). Models of misbelief: Integrating motivational and deficit theories of delusions. Consciousness and Cognition, 16(4), 932-941.

Miller, E., \& Wallis, J. (2009). Executive function and higher-order cognition: Definition and neural substrates. Encyclopedia of Neuroscience.

Morse, S. J. (1984). Undiminished confusion in diminished capacity. The Journal of Criminal Law and Criminology, 75(1).

Morse, S. J. (2003). Inevitable mens rea. Harvard Journal of Law and Public Policy, 27.

Morse, S. J. (2006a). Moral and legal responsibility and the new neuroscience. Neuroethics: Defining the issues in theory, practice, and policy, vol. 33. J. Illes. Oxford, New York: Oxford University Press. 50 p.

Morse, S. J. (2006b). Brain overclaim syndrome and criminal responsibility: A diagnostic note. 3 Ohio St. J. Crim. L.

Morse, S. J. (2007). Criminal responsibility and the disappearing person. Cordozo Law Review, 28, 2545

Morse, S. J. (2008). Determinism and the death of folk psychology: Two challenges to responsibility from neuroscience. Minnesota Journal of Law, Science and Technology, 9(1), 1-36.

Moscovitch \& Winocur (2002). The frontal cortex and working with memory. In D. T. Stuss \& R. R. Knight (Eds.), Principles of Frontal Lobe Function (pp. 188-209). New York: Oxford University Press.

MPC (1985). Model Penal Code and Commentaries (Official Draft and Revised Comments).

Olesen, P. J., Westerberg, H., \& Klingberg, T. (2004). Increased prefrontal and parietal activity after training of working memory. Nature Neuroscience, 7, 75-79.

Owen, A. M., Evans, A. C., \& Petrides, M. (1996). Evidence for a two-stage model of spatial working memory processing within the lateral prefrontal cortex. A positron emission tomography study. Cerebral Cortex, 6, 31-38.

Panetti v. Quarterman, 551 US 930 (2007)

People v. Dugan, 485 NE 2d 315 (1985).

Petrides, M. (2005). Lateral prefrontal cortex: Architectonic and functional organization. Philosophical Transactions of the Royal Society Series B, 360, 781-795. R v. Burgess, 2 QB 92A (1991).

R v. Parks, 2 SCR 871 (1992).

Raine, A., \& Yang, Y. (2006). Neural foundations to moral reasoning and antisocial behavior. SCAN(1), 203-213.

Ramnani, N., \& Owen, A. M. (2004). Anterior prefrontal cortex: Insights into function from anatomy and neuroimaging. Nature Reviews Neuroscience, 5(3), $184-194$.

Rensink, R. A., O’Regan, K., et al (2003). To see or not to see: The need for visual attention to perceive changes in scene. In B. J. Baars, W. P. Banks, \& J. B. Newman (Eds.), Essential sources in the scientific study of consciousness. Cambridge, MA: MIT Press.

Rex v. M'Naughten, 8 Eng. Rep. 718 (1843).

Rice, M., \& Harris, G. (1990). The predictors of insanity acquittal. International Journal of Law and Psychiatry, 13, $217-224$.

Roper v. Simmons, 543 US 551 (2005)

Roskies, A. (2006). Patients with ventromedial frontal damage have moral beliefs. Philosophical Psychology, 19(5), 617-627.

Sellars, W. (1956). Empiricism and the philosophy of mind. In H. Feigl \& M. Scriven (Eds.). The foundations of science and the concepts of psychoanalysis, Minnesota studies in the philosophy of science (Vol. 1, pp. 127-196). Minneapolis, MN: University of Minnesota Press.

Sharp, S., \& D'Cruz, O. F. (2002). Somnambulism. Emedicine(January), 1-10.

Smith, M. L., Kates, M. H., \& Vreizen, E. R. (1992). The development of frontal lobe functions. In F. Boller \& J. Grafman (Eds.), Handbook of Neuropsychology. New York: Elsevier.

Steinburg, L., \& Scott, E. S. (2003). Less guilty by reason of adolescence: Developmental immaturity, diminished responsibility, and the juvenile death penalty. American Psychologist, 58(12), 1009-1018.

Sternberg, R. (2010). Human intelligence. Amsterdam: Elsevier.

Terhune, D. B., Cardea, E., et al (2010). Dissociative tendencies and individual differences in high hypnotic suggestibility. Cognitive Neuropsychiatry.

Vincent, N. A. (2008). Neuroimaging and responsibility assessments. Neuroethics.

Woody, E. Z., \& Bowers, K. S. (1994). A frontal assault on dissociated control. In S. J. Lynn \& J. W. Rhue (Eds.), Dissociation: Clinical and theoretical perspectives. New York: Guilford. 